ESTUDIOS CERVANTINOS

219-231

\title{
LAS CORTES DE LA MUERTE, AUTO SACRAMENTAL ATRIBUIDO A LOPE DE VEGA, Y EL EPISODIO CERVANTINO DE LA CARRETA DE LA MUERTE (QUIJOTE, II, 11) ${ }^{1}$
}

Las Cortes de la Muerte, Sacramental Play attributed to Lope de Vega, and the Cervantes' Cart of Death episode (Quijote, II, 11)

Carlos Mata Induráin*

Resumen

Este trabajo se centra en la relación existente entre el episodio cervantino de la carreta de la Muerte (Quijote, II, 11) y el auto sacramental de Las Cortes de la Muerte, tradicionalmente atribuido a Lope de Vega. Esta pieza dramática ha recibido cierta atención por parte de la crítica debido a que, casi con total seguridad, tal es el auto mencionado en la Segunda parte del Quijote, cuando el caballero andante se encuentra con el carro en el que van los representantes de la compañía de Angulo el Malo. Tras reseñar brevemente el episodio cervantino y la posible identificación del auto en él mencionado, se ofrece un análisis dramático-literario de Las Cortes de la Muerte, comentando su estructura y otras cuestiones relativas a su construcción alegóricosimbólica.

Palabras clave: Lope de Vega. Cervantes. Auto sacramental. Don Quijote de la Mancha. Las Cortes de la Muerte. La carreta de la Muerte.

Abstract

This paper focuses on the relationship between Cervantes' Cart of Death episode (Quijote, II, 11) and the sacramental play entitled Las Cortes de la Muerte (The Parliament of Death), usually attributed to Lope de Vega. This play has received some attention by the critics because it is almost certainly the sacramental play mentioned in the second part of Don Quixote, when the knight-errant meets the actors belonging to the Angulo el Malo's company. After commenting on Cervantes' episode and the possible identification of the sacramental play mentioned there, the paper provides a dramatic and literary analysis of Las Cortes de la Muerte (The Parliament of Death), with comment about its structure and other details concerning its allegorical and symbolic constructions.

Key words: Lope de Vega. Cervantes. Sacramental Play. Don Quixote. The Parliament of Death. The Cart of Death

En este trabajo abordo la relación existente entre el auto sacramental de Las Cortes de la Muerte, atribuido a Lope de Vega, y el episodio cervantino de la carreta de la Muerte (Quijote, II, 11). Tres son los aspectos esenciales en los que voy a detenerme.

\footnotetext{
${ }^{1}$ Este trabajo forma parte del Proyecto "Autoridad y poder en el teatro del Siglo de Oro. Estrategias, géneros, imágenes en la primera globalización” (FFI2014-52007-P), financiado por el Ministerio de Economía y Competitividad del Gobierno de España.
} 
En primer lugar, recordaré brevemente los datos externos relativos al citado auto y aludiré al problema de la autoría (su atribución, no del todo segura, a Lope). En segundo término, centraré mi comentario en el motivo fundamental por el que este auto ha merecido cierta atención por parte de la crítica, y es el hecho de que, casi con total seguridad, este sea el auto de Las Cortes de la Muerte que se menciona en el capítulo 11 de la Segunda parte del Quijote, cuando el caballero andante se encuentra con el carro en el que marchan los representantes de la compañía de Angulo el Malo. En fin, en un tercer apartado abordaré, siquiera sea de forma muy somera, el análisis dramáticoliterario del auto, comentando su estructura y otras cuestiones relativas a su construcción alegórico-simbólica.

\section{El AUtO DE LAS CORTES DE LA MUERTE: DATOS EXTERNOS Y PROBLEMAS DE ATRIBUCIÓN}

El texto de este auto sacramental, que permanecía inédito, fue publicado por primera vez en 1892 por Marcelino Menéndez Pelayo en el volumen VIII de las Obras de Lope de Vega, el correspondiente a Autos y coloquios, II. En unas palabras de estudio preliminar explicaba el polígrafo santanderino que los comentadores del Quijote habían tratado de determinar cuál pudo ser el Auto de las Cortes de la Muerte a que Cervantes se refiere:

La obra que más a mano se ofrecía, y la que Clemencín insinuó el primero, es el notabilísimo Auto de las Cortes de la Muerte, a las cuales vienen todos los estados y, por vía de representación, dan aviso a los vivientes y doctrina a los oyentes: llevan gracioso y delicado estilo, pieza comenzada por el egregio vate placentino Micael de Carvajal, terminada por Luis Hurtado de Toledo, e impresa en la Imperial Ciudad por Juan Ferrer en 1557; obra, a la verdad, de las más notables de nuestro teatro primitivo, y de la cual se ha dicho, con justicia, que "pocas de su tiempo podrán competir con ella, ni en el artificio y facilidad del diálogo, ni en la gravedad de las sentencias, ni en la censura de las costumbres de la época, ni en la preparación e ingeniosísimo desempeño de algunas escenas". Esta composición, tan preciosa como rara [...], es sin duda la más original, la más poética y la más española de las distintas versiones que de la Danza de la Muerte tenemos en nuestra lengua. Pero no parece que puede ser aquella a que Cervantes alude, tanto por haber sido escrita en una época literaria anterior en más de medio siglo a la publicación del Quijote, y corresponder a un gusto diverso del que a principios del siglo XVII predominaba, cuanto por el hecho de no encontrarse entre los personajes del auto de Carvajal y Hurtado el Dios Cupido que Cervantes menciona, ni tampoco el Emperador, ni la Reina, ni el Soldado, aunque sí el Caballero y otras innumerables figuras. De donde se infiere, o que Cervantes citó de memoria, o que el Auto de las Cortes de la Muerte que representaba Angulo el Malo era muy distinto del de Miguel de Carvajal. Por otra parte, la libertad satírica y algo erasmiana que en todo este auto domina, especialmente tratándose de cosas y personas de la Iglesia, hace enteramente inverosímil el que siguiera representándose a principios del siglo XVII. 
Tampoco afirmaremos que el auto a que se alude en el Quijote sea el que insertamos en esta colección, porque no todas las señas convienen. Manuscrito le encontramos, en copia del mismo de don Justo de Sancha, benemérito bibliófilo, que coleccionó el Romancero y Cancionero sagrados, pero que al publicarle en 1855 aún no tenía noticia de este nuevo Auto de las Cortes de la Muerte. Sobre su autoridad va nuestro texto, que en el original que él vio, no sabemos si manuscrito o impreso, llevaba los nombres de Lope de Vega y del Dr. Mira de Amescua, el primero al frente del auto, el segundo al frente de la loa. No respondemos de tales atribuciones, pero de todos modos no hemos querido omitir una composición positivamente antigua e ingeniosa, por más que en nada acreciente la gloria de los dos ilustres poetas a quienes se ha prohijado (248-249).

En fechas más recientes, Amparo Izquierdo Domingo -investigadora que ha abordado el análisis en profundidad de los autos sacramentales de Lope; ver sus trabajos de 2013a y 2014- ha resumido los datos esenciales relativos a la transmisión textual y la autoría de este auto. Indica, en efecto, que el texto

se considera original de Lope, a pesar de que la loa la firme [...] Mira de Amescua. Flecniakoska (1961, pp. 49-51) duda de la autoría de este auto impreso por Menéndez Pelayo e incluso lo elimina de su lista de autos de Lope por considerarlo una mezcolanza de comedias, autos y entremeses de autores como Lope, Tárrega, Francisco de Rojas, Tirso de Molina y Quiñones de Benavente. Rennert y Castro (1969, pp. 501 y ss.) dudan asimismo de la autoría de este auto (Estado de la cuestión, 504).

Ciertamente, esta cuestión de la autoría lopesca no es esencial para el análisis que ahora me ocupa. Como sucede con otros autos (también, por ejemplo, con el de $L a$ Araucana: ver Mata Induráin), tras ser editado por Menéndez Pelayo formando parte del corpus dramático del Fénix, la crítica lo viene considerando obra suya. En cualquier caso, y en la imposibilidad de aportar otros datos que corroboren o descarten definitivamente tal autoría, me parece oportuno consignar las dudas existentes, señalando -así lo he hecho en mi título- que se trata de un auto sacramental "atribuido a Lope de Vega".

\section{LA RELACIÓN DEL AUTO CON EL EPISODIO DE QUIJOTE, II, 11}

Antes que todo, convendrá recordar lo que sucede en el capítulo 11 de la Segunda parte de Don Quijote de la Mancha, titulado "De la estraña aventura que le sucedió al valeroso don Quijote con el carro o carreta de Las Cortes de la Muerte". El caballero manchego y su fiel escudero van conversando acerca del encantamiento de Dulcinea; Sancho, tras expresar su preocupación ante la posibilidad de que los gigantes y caballeros que venza su amo no puedan encontrar a Dulcinea (por estar encantada), muestra su disposición a emprender nuevas aventuras:

Responder quería don Quijote a Sancho Panza, pero estorbóselo una carreta que salió al través del camino cargada de los más diversos y estraños personajes y 


\section{Carlos Mata Induráin}

figuras que pudieron imaginarse. El que guiaba las mulas y servía de carretero era un feo demonio. Venía la carreta descubierta al cielo abierto, sin toldo ni zarzo. La primera figura que se ofreció a los ojos de don Quijote fue la de la misma Muerte, con rostro humano; junto a ella venía un ángel con unas grandes y pintadas alas; al un lado estaba un emperador con una corona, al parecer de oro, en la cabeza; a los pies de la Muerte estaba el dios que llaman Cupido, sin venda en los ojos, pero con su arco, carcaj y saetas. Venía también un caballero armado de punta en blanco, excepto que no traía morrión ni celada, sino un sombrero lleno de plumas de diversos colores. Con estas venían otras personas de diferentes trajes y rostros. Todo lo cual visto de improviso, en alguna manera alborotó a don Quijote y puso miedo en el corazón de Sancho; mas luego se alegró don Quijote, creyendo que se le ofrecía alguna nueva y peligrosa aventura, y con este pensamiento, y con ánimo dispuesto de acometer cualquier peligro, se puso delante de la carreta y con voz alta y amenazadora dijo:

- Carretero, cochero o diablo, o lo que eres, no tardes en decirme quién eres, a dó vas y quién es la gente que llevas en tu carricoche, que más parece la barca de Carón que carreta de las que se usan.

A lo cual, mansamente, deteniendo el Diablo la carreta, respondió:

- Señor, nosotros somos recitantes de la compañía de Angulo el Malo. Hemos hecho en un lugar que está detrás de aquella loma, esta mañana, que es la octava del Corpus, el auto de Las Cortes de la Muerte, y hémosle de hacer esta tarde en aquel lugar que desde aquí se parece; y por estar tan cerca y escusar el trabajo de desnudarnos y volvernos a vestir, nos vamos vestidos con los mesmos vestidos que representamos. Aquel mancebo va de Muerte; el otro, de Ángel; aquella mujer, que es la del autor, va de Reina; el otro, de Soldado; aquel, de Emperador, y yo, de Demonio, y soy una de las principales figuras del auto, porque hago en esta compañía los primeros papeles. Si otra cosa vuestra merced desea saber de nosotros, pregúntemelo, que yo le sabré responder con toda puntualidad, que, como soy demonio, todo se me alcanza (713-714).

Stefano Arata, en su lectura explicativa del capítulo, comenta al respecto que este encuentro sucede durante la semana de las fiestas del Corpus Christi, la llamada octava del Corpus ${ }^{2}$, "cuando las compañías teatrales, tras haber actuado en las procesiones de las capitales, solían llevar sus autos sacramentales a los pueblos de la comarca" (132). Ya sabemos que Cervantes fue un gran hombre de teatro -género en el que también quiso triunfar, aunque ahí se topó con la exitosa fórmula del Fénix, bien distinta de la suya-, y que estaba muy atento a todas las novedades teatrales de su tiempo, que conocía muy bien - como demuestra, por otra parte, la "teatralidad" del Quijote, en especial su Segunda parte-, de ahí que no deba extrañarnos el carácter documental de este episodio, como ha puesto de relieve la crítica; cito de nuevo a Arata:

Todo, en la descripción de la carreta de actores que se cruza en el camino de DQ, responde a la esfera de la verdad histórica, de forma casi documental. Existió

\footnotetext{
${ }^{2}$ Dato que rompe la cronología interna del Quijote... pero esa es otra cuestión.
} 
realmente el autor de comedias Andrés de Angulo "el Malo", cuya compañía era una de las más afamadas de la época; el auto sacramental de Las Cortes de la Muerte que los actores acaban de representar, se puede identificar con una pieza de Lope de Vega, cuyo texto ha llegado hasta nosotros, y la descripción del atuendo de los faranduleros reproduce casi literalmente las indicaciones de vestuario del manuscrito lopesco. También el extraño personaje que aparece junto a la carreta - ese bojiganga que hace sonar unos cascabeles y esgrime un palo con unas vejigas de vaca-, procede de la viva realidad de las fiestas del Corpus. Se trata de una figura carnavalesca, personificación de la Locura, que precedía a los carros durante las procesiones, asustando con sus saltos y con un palo a los espectadores. Según la zona geográfica, se le conocía con el nombre de botarga, mojarrilla o moharracho (132).

El resto del episodio cervantino se puede resumir brevemente: consiste en la aparición del moharracho, "uno de la compañía que venía vestido de bojiganga, con muchos cascabeles, y en la punta de un palo traía tres vejigas de vaca hinchadas" (715); su fracasado intento de robo del rucio (el Diablo lo deja marchar y la bestia vuelve tranquilamente a su querencia); las prevenciones de Sancho contra los farsantes, "que es gente favorecida" (716); los gritos de don Quijote, que quiere arremeter contra el "gallardo escuadrón" (717) que forman los de la carreta, los que se previenen con piedras para dar una buena "sopa de arroyo" (717) a su atacante; finalmente, cómo Sancho convence a su amo de que es mejor no enfrentarse a ellos diciendo que "entre todos los que allí están, aunque parecen reyes, príncipes y emperadores, no hay ningún caballero andante" (717). Esta advertencia de "Sancho bueno, Sancho discreto, Sancho cristiano y sincero" (717) constituye un argumento de peso para don Quijote, que queda convencido y vuelve las riendas de Rocinante; "la Muerte con todo su escuadrón volante volvieron a su carreta y prosiguieron su viaje", y "este felice fin tuvo la temerosa aventura de la carreta de la Muerte" (718).

Veamos ahora lo relativo a la identificación de ese auto que representaba la compañía de Angulo el Malo. Leonard Mades, en un trabajo de 1968, analizaba los intentos de localizar la fuente del episodio de Quijote, II, 11: el auto de Las Cortes de la Muerte comenzado por Micael de Carvajal y terminado por Luis Hurtado de Toledo; un episodio del Amadís de Gaula (II, XII) y alguna hipotética obra del propio Cervantes. Repasa las pruebas ofrecidas para establecer como fuente el auto de Carvajal y Hurtado, escrito hacia 1557 (y editado por Justo de Sancha en 1855). Revisaba también las opiniones de Menéndez Pelayo, Cortejón, Rodríguez Marín, etc. Tras ello, Mades afirmaba categóricamente que "hay que rechazar como posibilidad, ojalá para siempre, el auto de Carvajal y Hurtado" (340). En efecto, solo cuatro personajes de este auto aparecen en el Quijote: la Muerte, el Diablo, el Caballero y el Ángel; y es mucho más extenso que el de Lope, con lo que no lo representaría una compañía pequeña como la bojiganga que se menciona en el Quijote. En cambio, de los diez personajes del auto de Lope, ocho corresponden por nombre o descripción con los mencionados en la novela: la Muerte, el Pecado, la Locura, el Tiempo, el Hombre, el Ángel de la Guarda, el Diablo 


\section{Carlos Mata Induráin}

y "el dios que llaman Cupido". Sigue indicando Mades que los dos personajes del auto que no se encuentran en el Quijote son el Niño Dios, que va vestido de pastorcico, y la Envidia, de villano rústico (341), para concluir:

Hay que convenir con Cortejón, Sancha y Menéndez Pelayo en que no se puede afirmar con una seguridad completa que el auto atribuido a Lope sea el que recuerda Cervantes. Pero, de las obras propuestas como fuente hasta aquí, es sin lugar a duda la más probable, acusando notables semejanzas al episodio del Quijote (342).

Antonio Regalado (413) lo ha estudiado en relación con el tema más amplio de la influencia de Cervantes sobre Calderón. En el año 2002 Carlos Jáuregui, que edita Las Cortes de la Muerte (1557), dedica en la introducción un apartado a "El carro de las Cortes de la Muerte que vio don Quijote" (28-33). Repasa ahí algunos autores que creen que fue el de Carvajal, como Valentín de Pedro, para quien "aquel auto de Las Cortes de la Muerte era - y no podía ser otro- que el que compusieron Micael de Carvajal y Luis Hurtado de Toledo" (45); o Mary M. Gaylord, quien señala que, aunque no podemos estar seguros de que Cervantes conociera el auto de Carvajal, la evidencia textual proveniente del capítulo 11 sugiere que, al menos, lo tenía en mente (141, nota 24). Por su parte, Jáuregui explica que en la obra de Carvajal no están todos los personajes de la carreta de Angulo el Malo como la Reina y Cupido, y afirma:

Sin descartar la posibilidad de que, en efecto, las Cortes de Carvajal hubieran gozado de cierta popularidad y que hubieran sido representados algunos de sus retablos, debe subrayarse que la obra que va a representar la carreta de Angulo el Malo parece ser más bien el auto Las Cortes de la Muerte, atribuida a Lope de Vega (33).

Incluye Jáuregui un cuadro comparativo de los personajes del Quijote, el auto de Lope y el de Carvajal (31-32). Tras comentarlo, concluye que "La coincidencia textual entre las descripciones de los personajes del auto de Lope y las de los personajes de la carreta en Don Quijote permite conjeturar que Cervantes tuvo en mente el auto de Lope y no el de Carvajal" (33).

Por su parte, Percas de Ponseti, estudió en 2003 el episodio de Quijote II, 11 como un ataque contra Lope por parte de Cervantes, quien aludiría a su auto (69, nota 17). Para Jiménez Silva, Cervantes ridiculiza "con sana crítica tales dramas y a los que los ejecutan" (67). En fin, James Iffland, en un trabajo de 2012, se centra en el análisis de lo festivo presente en el auto, sin entrar en la cuestión de la autoría.

En definitiva, a la luz de lo indicado por la crítica (en especial, los argumentos de Mades), la hipótesis más probable es que el auto de Las Cortes de la Muerte que llevaba en su repertorio la compañía de Angulo el Malo fuera el más tardío, el atribuido a Lope, cuya estructura y elementos alegórico simbólicos analizaré - de forma muy sucinta- a continuación. 


\section{ANÁLISIS DRAMÁTICO-LITERARIO DE LAS CORTES DE LA MUERTE}

El auto de Las Cortes de la Muerte adopta la estructura de juicio en un tribunal, que es uno de los paradigmas compositivos habituales en los autos sacramentales. Ya en el Códice de autos viejos hay una Farsa del sacramento de las Cortes de la Iglesia; podemos recordar también Las pruebas de Cristo de Mira de Amescua, y en Calderón es una estructura dramática recurrente (véase, especialmente, El pleito matrimonial del cuerpo y el alma). Ignacio Arellano ha estudiado la presencia de este esquema compositivo en Calderón: "Uno de los paradigmas más importantes, muy apto para expresar los conflictos y enfrentamientos básicos en el auto, es el del pleito o juicio" $(33)^{3}$. En el caso de esta obra atribuida a Lope, esas Cortes de la Muerte equivalen en el plano alegórico al Juicio Final en el que Dios premia a los justos y castiga a los pecadores. El tema se inserta además en la larga tradición de las danzas de la muerte medievales, tema estudiado por Víctor Infantes en una documentada monografía.

La estructura global ${ }^{4}$ de la pieza es la celebración de unas Cortes de la Muerte (Juicio Final en la lectura alegórico-simbólica), con inserción al medio de una escena de teatro dentro del teatro en la que la Locura escenifica el ambiente de las fiestas populares del Corpus. El auto se cierra con el arrepentimiento del Hombre, pero sobre todo con la contraposición Muerte / Vida, identificada esta con el manjar eucarístico, que es Pan de vida eterna. A continuación, examinaré con más detalle la estructura del auto.

1) En el bloque inicial (vv. 1-273 ) el Tiempo resume la historia de la creación del mundo y, luego, la historia del pueblo de Israel (vv. 45-131). El Pecado le pide que se detenga en su relato cuando llega el Hombre, "a quien hoy / robar y prender tenemos" (vv. 133-134).

2) La parte nuclear del auto corresponde a la escenificación de las Cortes de la Muerte (vv. 274-742). La Muerte declara abierta la asamblea y, en un primer momento, se suceden cuatro parlamentos de la Locura (vv. 283-414), el Diablo (vv. 417-468), el Pecado (vv. 471-539) y el Ángel (vv. 541-709), que se cierran con una coda en forma de breve diálogo entre la Envidia y el Ángel (vv. 710-742). Los tres primeros discursos -bastante parecidos entre sí, desde el punto de vista funcional-insisten en la caducidad de todo lo terreno (con manejo de los tópicos habituales del tempus fugit, el Ubi sunt?, la vanitas vanitatum...) y en el poder igualador de la muerte. La Locura, por ejemplo, echando mano de una estructura muy usual en el teatro del Siglo de Oro, dice:

Locura Todo es lisonja y engaño, todo es locura y soberbia:

\footnotetext{
${ }^{3}$ Arellano dedica un apartado de su libro a los paradigmas de "Juicios, pleitos, y sus derivaciones (certamen académico, juicio penal, inquisitorial, auto de fe...)" (33-38).Ver también Fothergill-Payne (57-62).

${ }^{4}$ Dejo de lado ahora el análisis de la loa. Tampoco puedo ocuparme de la interesante relación existente entre el episodio cervantino y la mojiganga de Calderón Las visiones de la Muerte. Para la influencia de Cervantes en Calderón ver, entre otros, los trabajos de Sánchez, Meregalli y, sobre todo, Arellano (1999).

${ }^{5}$ Todas las citas se hacen por mi edición (en preparación) de Las Cortes de la Muerte, con su correspondiente numeración de versos.
} 


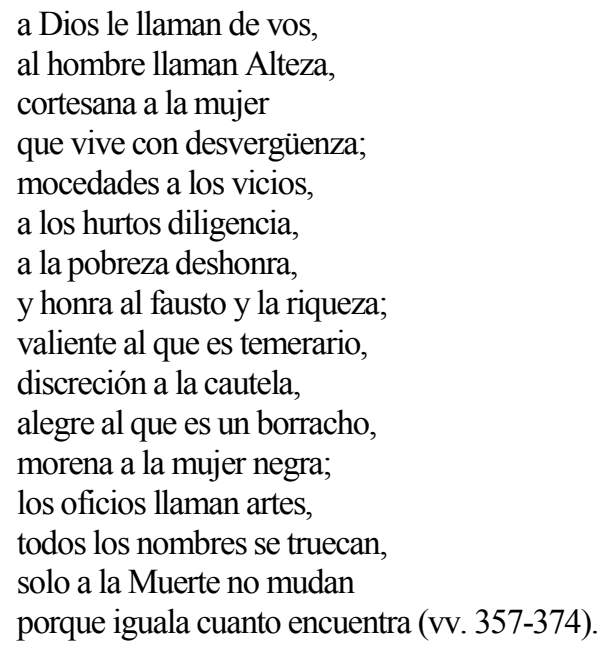

Estas otras palabras corresponden al parlamento del Diablo:

Diablo El santo amor desfallece, el apetito se encumbra, la Verdad anda arrastrada, la Mentira reina y triunfa; la Lisonja en la privanza a la Fe crédito usurpa; la maldad camina en coche, la bondad sola y desnuda. La Justicia sin balanzas, con más vela que una grulla, pesca con vara y anzuelo en lagunas de agua turbia (vv. 441-452).

Véanse igualmente estos otros cuatro versos-en construcción anafórica-del Pecado:

Pecado Todo es sombras y apariencias, todo sueños y visiones, todo antojos e ilusiones, todo horrores y violencias (vv. 475-478).

En respuesta a estos tres discursos de Locura, Diablo y Pecado, el parlamento del Ángel -la Muerte le da ahora la palabra- se centra en las cuatro postrimerías (Muerte, Juicio, Infierno y Gloria). Tras describir las penas del infierno (en el que padecen todos los pecadores, con mención expresa de un largo listado de distintas herejías en los vv. 668-685), expone que la única salvación se encuentra en el "manjar sacrosanto" que es el Pan de la Eucaristía: 


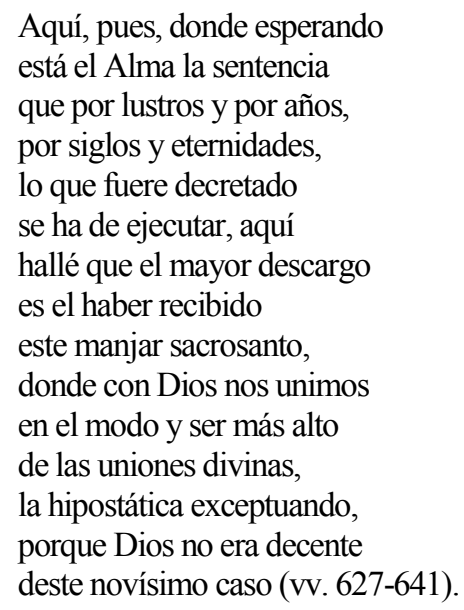

3) Una escena intercalada (vv. 743-838) es la descripción de las fiestas del Corpus que hace la Locura; se trata de un caso de teatro dentro del teatro en el que la Locura canta, se disfraza de gigantilla, etc., reproduciendo elementos habituales de las celebraciones propias del Corpus, así como indican las diversas acotaciones escénicas: ("Saca la Locura una guitarrilla y canta", acot. tras v. 778), "Se coloca la Locura una tunicela por la cabeza, con cuernos para denotar es el Diablo, y sigue representando", acot. tras v. 782; "Quitase ahora la tunicela de demonio y pónese otra blanca y una cabellera rubia, y representa", acot. tras v. 797; "Vase la Locura y sale luego en cuclillas haciendo la gigantilla", acot. tras v. 820).

4) Las Cortes se reanudan con el parlamento del Hombre (vv. 839-1026), el que se divide en dos partes. La primera es una definición de la Muerte (vv. 839-946), expresada por medio de una estructura anafórica ("Es la Muerte..." o "Es Muerte..." y una serie de elementos definitorios):

\author{
Hombre Es la Muerte ejecutor \\ que a nuestra naturaleza \\ cita al nacer, y al morir \\ por remates saca prendas (vv. 847-850). \\ Hombre Es la Muerte un mirador \\ de donde claro se ojea \\ lo profundo de la culpa \\ y lo largo de la pena (vv. 859-862). \\ Hombre Es Muerte reloj de sol \\ cuyas sombras nos enseñan \\ las horas que van pasando \\ y las pocas que nos quedan (vv. 907-910).
}


Hombre Es la Muerte un artillero

que a todas edades llega,

que están cuna y ataúd

en igual distancia della (vv. 923-926).

Por contraste, sigue su definición de la Vida (vv. 947-1027), identificada como ya indicaba antes con el "Pan celestial" de la Eucaristía, que constituye el remedio de todos los pecados y culpas del Hombre que antes se habían ido describiendo:

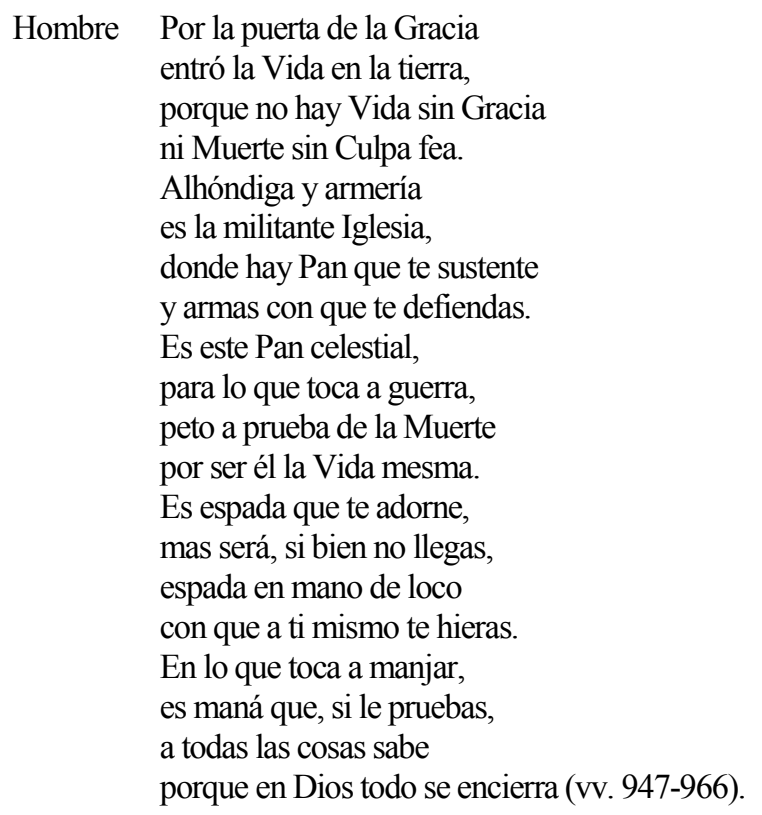

5) En fin, el remate de la pieza lo constituye la escena del Juicio Final (vv. 10271108 ), en la que un Niño Dios vestido de pastorcico hace justicia, separando los corderos blancos, a los que pone a su diestra, de los corderos negros, que quedan a la izquierda: Los cabritos negros se hunden en el tablado, saliendo llamas de fuego con ruido de truenos. Desaparecen todos, quedando solos el Niño Dios, el Ángel y el Hombre (acot. tras v. 1060). Es muy hermosa la canción que sigue, invitando a permanecer en vela:

Música Vela, vela, pecador,

mira que el mundo te engaña,

que anda el lobo en la campaña:

huye y teme su rigor (vv. 1061-1064).

El Hombre arrepentido declama un soneto (son unos versos de escasa calidad poética, logrados con rimas pobres, en su mayoría gerundios e infinitivos) que comienza "Si lo puedo decir, a mi malicia...." Y de nuevo la Música canta: 


$\begin{aligned} \text { Música } & \text { No quiere, no, el Redentor } \\ & \text { la muerte del pecador; } \\ & \text { si que muera arrepentido, } \\ & \text { pues perdonar al vencido } \\ & \text { es gloria del vencedor (vv. 1091-1095). }\end{aligned}$

El Ángel comenta que a quien así lo haga le espera el premio de la Gloria en el Cielo, "que es el mismo Dios / con su bendición eterna" (vv. 1103-1104). Y en el ultílogo, que corresponde al Hombre, se recuerda -como era habitual en el teatro áureoel título de la pieza:

\author{
Hombre Y Yquí da fin-no os asombre- \\ el auto, de aquesta suerte, \\ de Las Cortes de la Muerte \\ con las miserias del Hombre (vv. 1105-1108).
}

\title{
4. A MODO DE CONCLUSIÓN
}

En general, el auto de Las Cortes de la Muerte tradicionalmente atribuido a Lope de Vega es una obra que presenta muy escasa acción dramática; predomina en él un tono bastante estático, con la yuxtaposición en su parte nuclear de cuatro parlamentos formados cada uno por una larga tirada de versos (en algunos casos, más de un centenar), estructura discursiva que apenas hace avanzar la acción. Por otra parte, la profundidad teológico-doctrinal de la pieza (fuese Lope su autor, fuese otro ingenio) no es - eso se advierte claramente- la misma que apreciamos en los autos sacramentales de Calderón, que constituyen la cumbre del género, también por la perfección de su desarrollo alegórico-simbólico y las complejas redes de correspondencias que se establecen en ellos entre los planos real y figurado. Algo más interesante resulta el ornato retórico del texto, que en esta ocasión no he podido analizar. Sea como fuere, el mayor interés de Las Cortes de la Muerte estriba en que -casi con total seguridad- este era el auto que llevaba en su repertorio la compañía de Angulo el Malo, así como leemos en el famoso episodio del carro o carreta de la Muerte (Quijote, II, 11).

Universidad de Navarra * Grupo de Investigación Siglo de Oro (GRISO) Edificio Biblioteca 31009 Pamplona (España) cmatain@unav.es

\section{OBRAS CITADAS}

Arata, Stefano. “Capítulo XI". En Miguel de Cervantes. Don Quijote de la Mancha. Ed. dirigida por Francisco Rico. Barcelona: Instituto Cervantes / Crítica, 1998. Vol. complementario: 132-134. 
Arellano, Ignacio. Estructuras dramáticas y alegóricas en los autos de Calderón. Kassel: Edition Reichenberger, 2001.

— “Cervantes en Calderón". Anales cervantinos XXXV (1999): 9-35.

Calderón de la Barca, Pedro. Las visiones de la muerte. En Entremeses, jácaras y mojigangas. Ed. de Evangelina Rodríguez y Antonio Tordera. Madrid: Castalia, 1983: 369-384.

De Cervantes, Miguel. Don Quijote de la Mancha. Ed. dirigida por Francisco Rico. Barcelona: Instituto Cervantes / Crítica, 1998.

De Pedro, Valentín. América en las letras españolas del Siglo de Oro. Buenos Aires: Sudamericana, 1954.

De Vega, Lope. Las Cortes de la Muerte. Auto sacramental. En Obras de Lope de Vega, VIII, Autos y coloquios, II (BAE, 159). Ed. y estudio preliminar de Marcelino Menéndez Pelayo. Madrid: Atlas, 1963: 461-476.

Las Cortes de la Muerte. Ed. de Carlos Mata Induráin. Kassel / Pamplona: Edition Reichenberger / Universidad de Navarra, en preparación.

Fothergill-Payne, Louise. La alegoría en los autos y farsas anteriores a Calderón. London: Tamesis Books Limited, 1977.

Gaylord, Mary M. 'Pulling Strings with Master Peter's Puppets: Fiction and History in Don Quixote". Cervantes. Bulletin of the Cervantes Society of America 18:2 (1998): 117-147.

Iffland, James. "Don Quijote ante Las Cortes de la Muerte: reflexiones sobre la intertextualidad festiva". Revista eHumanista/Cervantes 1 (2012): 605-615.

Infantes, Víctor. Las danzas de la muerte. Génesis y desarrollo de un género medieval (siglos XIII-XVII). Salamanca: Ediciones Universidad de Salamanca, 1997.

Izquierdo Domingo, Amparo. Los autos sacramentales de Lope de Vega: funciones dramáticas. New York: IDEA, 2014.

— Los autos sacramentales de Lope de Vega: clasificación e interpretación. Vigo: Academia del Hispanismo, 2013a.

_ "Los autos sacramentales de Lope de Vega: estado de la cuestión y propuesta de estudio". Teatro de Palabras. Revista sobre teatro áureo 7 (2013b): 497-515.

Jáuregui, Carlos. Querella de los indios en las "Cortes de la Muerte" (1557) de Michael de Carvajal. México: Universidad Nacional Autónoma de México, 2002.

Jiménez Silva, Roberto. "Un drama sacro en el Quijote: Las Cortes de la Muerte". En Homenaje académico al "Quijote" en el IV Centenario de su publicación. Toledo: Real Academia de Bellas Artes y Ciencias Históricas de Toledo, 2006: 65-71.

Mades, Leonard. "El auto de Las cortes de la Muerte mencionado en el Quijote". Revista Hispánica Moderna XXXIV (1968): 338-343.

Mata Induráin, Carlos. "La guerra de Arauco en clave alegórica: el auto sacramental de $\mathrm{La}$ Araucana". Alpha 33 (2011): 171-186.

Menéndez Pelayo, Marcelino. "Loa y auto sacramental de Las cortes de la Muerte". En Obras de Lope de Vega, VII, Autos y coloquios, II. Madrid: Atlas, 1963: 247-249. 
Meregalli, Franco. "Cervantes en Calderón”. En Antonella Cancellier, Donatella Pini Moro y Carlos Romero (eds.). Atti delle Giornate Cervantine Padua: Unipress, 1995: 127-135.

Percas de Ponseti, Helena. "Cervantes y Lope de Vega: postrimerías de un duelo literario y una hipótesis". Cervantes. Bulletin of the Cervantes Society of America 23:1 (2003): 63-115.

Regalado, Antonio. "Cervantes y Calderón: el gran teatro del mundo". Anales cervantinos XXXV (1999): 407-417.

Sánchez, Alberto. "Reminiscencias cervantinas en el teatro de Calderón". Anales cervantinos VI (1957): 262-270. 